\title{
Fibronectin molecular status determination useful to differentiate between rheumatoid arthritis and systemic lupus erythematosus patients
}

\author{
Magdalena Przybysz • Krzysztof Borysewicz • \\ Iwona Kạtnik-Prastowska
}

Received: 22 June 2011 / Accepted: 8 December 2011 / Published online: 4 January 2012

(C) The Author(s) 2012. This article is published with open access at Springerlink.com

\begin{abstract}
To find whether the plasma fibronectin (FN) molecular status can be useful to differentiate between rheumatoid arthritis (RA) and systemic lupus erythematosus (SLE). The expression of plasma FN domains was determined by ELISA using monoclonal domain-specific antibodies. FN molecular forms were revealed by immunoblotting and analyzed by densitometry. The following findings were found: (1) Mean values of ${ }^{\text {Fibrin-Heparin }} \mathrm{FN}$ concentration were lower in SLE and RA patients than in normal plasmas. The cut off points at $31 \mathrm{mg} / \mathrm{l}$ in SLE and at $45 \mathrm{mg} / \mathrm{l}$ in RA showed a sensitivity and specificity of 54,55 and $75 \%$, respectively. (2) Mean values of concentrations of ${ }^{\mathrm{CBD}} \mathrm{FN}$ and ${ }^{\mathrm{Ct}} \mathrm{FN}$ were lower in SLE than those in normal and RA plasmas. Quantified data showed the cut off points of ${ }^{\mathrm{CBD}} \mathrm{FN}$ and ${ }^{\mathrm{Ct}} \mathrm{FN}$ at $200 \mathrm{mg} / \mathrm{l}$ (58\% of sensitivity, 56\% of specificity) and $350 \mathrm{mg} / \mathrm{l}$ (58\% of sensitivity, $58 \%$ of specificity) in SLE, as well as at $295 \mathrm{mg} / \mathrm{l}$ (52\% of sensitivity, $51 \%$ of specificity) and $460 \mathrm{mg} / \mathrm{l}$ in RA (70\% of sensitivity, $73 \%$ of specificity). (3) The plasma FN immunopatterns, characterized by the presence of high-molecular (260$310 \mathrm{kDa}$ ) and/or low-molecular (158-209 kDa) FN bands, were specific only for SLE samples. The analysis of plasma FN status revealed by its Fibrin-Heparin-, CBD- and
\end{abstract}

\footnotetext{
M. Przybysz ( $\square) \cdot$ I. Kątnik-Prastowska

Department of Chemistry and Immunochemistry,

Wrocław Medical University, Bujwida 44a,

50-345 Wrocław, Poland

e-mail: mprzyb@immchem.am.wroc.pl

I. Kątnik-Prastowska

e-mail: iwona@immchem.am.wroc.pl

K. Borysewicz

Department and Clinic of Rheumatology and Internal Medicine,

Wrocław Medical University, Borowska 213,

50-556 Wrocław, Poland
}

Ct-domain reactivity with monoclonal antibody and immunoblotting can be helpful to differentiate the SLE in respect to RA and normal plasmas.

Keywords Fibronectin - Fibronectin fragments . Fibronectin domains $\cdot$ Rheumatoid arthritis $\cdot$ Systemic lupus erythematosus

\section{Introduction}

Rheumatoid arthritis (RA) and systemic lupus erythematosus (SLE) belong to the group of inflammatory rheumatic diseases. Diagnosing of RA and SLE is a clinically driven process using different biomarkers which could be informative to prescribe disease susceptibility, diagnosis and activity [1]. Among potential SLE biomarkers are: anti-dsDNA and anti-nucleosome autoantibodies, complement, acute phase proteins, cytokines and soluble cytokine receptors [2]. In RA, inflammatory markers, autoantibodies and bone markers potentially prognose radiological damage $[3,4]$.

Fibronectin (FN) is a multidomain and multifunctional glycoprotein engaged in processes associated with cellmatrix interactions. It is reported to play an important role in extracellular matrix (ECM) remodeling, adhesion, migration, proliferation, transformation, tissue repair, wound healing and hemostasis [5]. FN found in the ECM originates from various cells (e.g., fibroblasts, chondrocytes), is trapped into insoluble multimeric fibrills, while that present in plasma derives from liver hepatocyte synthesizes, and is a soluble, compact globular dimer [6]. Plasma FN is believed to be biologically inactive. Although in the presence of endothelial injury and during the repair processes, the plasma FN can enter the extravascular space, changes the conformation from globular to fibrillar, forms 
multimers and aggregates to form a provisional matrix [7]. FN is able to bind, via its multiple domains, a number of macromolecules, including fibrin, fibrinogen, heparin, collagen, C-reactive protein, rheumatoid factor and complement components [8].

Our previous results indicate profound degradation of synovial FN in RA occurs only locally in joint tissues, the primary site of the pathology. In the RA blood plasma, FN did not undergo fragmentation, and some of its domain expressions, although higher than those of normal plasma FN, were not associated with RA progression [9]. In the present work, we were focused whether the plasma FN concentration and FN molecular status revealed by immunoblotting in other than RA arthritis disease, namely SLE, can be related to the disease and may help to state the differential diagnosis. FN concentration was determined by ELISA with a set of specific monoclonal antibodies able to react with epitopes of structurally and functionally independent FN domains: the cell- $\left({ }^{\mathrm{CBD}} \mathrm{FN}\right)$, collagen- $\left({ }^{\mathrm{Collagen}} \mathrm{FN}\right)$, fibrin( $\left.{ }^{\text {Fibrin }} \mathrm{FN}\right)$, fibrin-heparin-binding $\left({ }^{\text {Fibrin-Heparin }} \mathrm{FN}\right)$, and to carboxy-terminal ( $\left.{ }^{\mathrm{Ct}} \mathrm{FN}\right)$ region. However, it should be underline that the FN level determination by a domain-specific monoclonal antibody reflects not only the FN concentration but also the presence of FN molecule in a dynamic form, engaged, or not, in biological reactions of its domains.

\section{Materials and methods}

Patients and samples

Patients $(n=41)$ who were attending the Rheumatology Clinic of the Wroclaw Medical University were included in the study after their informed consent had been given. Twenty-two samples were derived from RA patients and nineteen samples derived from patients with SLE patients (Table 1). The study was approved by the local ethics committee (approval no 453/2007). All patients were evaluated from the results of clinical examination, plain X-rays findings and routine laboratory blood plasma parameters. Patients who had traumatic, septic, or microcrystalline arthritis, previous joint surgery, or isotopic synovectomy within the 12 months before the study were excluded. Blood was drawn from patients into plastic syringes and placed directly into tubes containing $1 \mathrm{mM}$ phenylmethylsulfonyl fluoride (PMSF, Sigma Chemical Co, St Louis, MO, USA). The samples were centrifuged, and blood plasmas were stored in small aliquots at $-78^{\circ} \mathrm{C}$ until used.

RA was diagnosed according to ACR (American College of Rheumatology) classification criteria from 1987 [10]. All patients suffered more than 2 years, and with respect to the radiographic outcome by scoring the X-rays of the patients' hands, the RA blood plasma samples were
Table 1 Characteristics of RA and SLE patients

\begin{tabular}{lll}
\hline Patients & RA & SLE \\
& $n=22$ & $n=19$ \\
\hline Demographics & & \\
Age (years) & $60 \pm 11$ & $46 \pm 15.3$ \\
Gender & 13 & \\
Male & 9 & 6 \\
Female & $150 \pm 74$ & $78 \pm 44.2$ \\
Disease duration (months) & $23 \pm 14$ & $37 \pm 23$ \\
ESR (mm/h) & $8 \pm 7$ & $15.4 \pm 15.2$ \\
CRP (mg/l) & & \\
Therapy & 18 & 15 \\
Steroid therapy & 7 & 4 \\
Methotrexat & & 3 \\
NSAIDs & 1 & 4 \\
Sulphasalazin & & \\
Cyclophosphamid & 2 & \\
Azathioprini & & \\
No therapy & & \\
\hline NAlDs nonterol & & \\
\hline
\end{tabular}

NSAIDs nonsteroidal anti-inflammatory drugs, ESR erythrocyte sedimentation rate, $C R P$ C-reactive protein

classified as a late RA [11]. SLE was diagnosed based on modified 1997 classification criteria for SLE [12].

All patients had active disease according to DAS28 [DAS-Disease Activity Score] for RA patients and SLEDAI [Systemic Lupus Erythematosus Disease Activity Index] for SLE patients, and some inflammatory markers such as ESR or/and CRP .

A normal group was formed by the blood plasma collected from 22 healthy individuals, $18-73$ years old, mean age, $46 \pm 17$; median age, 44 years.

FN concentration based on the reactivity with the domainspecific monoclonal antibodies

FN concentration was determined based on the immunoreactivity of conformationally accessible epitopes on the cell- $\left({ }^{\mathrm{CBD}} \mathrm{FN}\right)$, collagen- $\left({ }^{\mathrm{Collagen}} \mathrm{FN}\right)$, second fibrin- $\left({ }^{\mathrm{Fibrin}} \mathrm{FN}\right)$, $N$-terminal heparin and fibrin- $\left({ }^{\text {Fibrin-Heparin }} \mathrm{FN}\right)$ binding domains and on sequences located at the carboxy-terminal part of FN ( ${ }^{\mathrm{Ct}} \mathrm{FN}$ ) (Fig. 1) with the five well-defined monoclonal antibodies (TaKaRa, Shuzo Co., Shiga, Japan), anti${ }^{\mathrm{CBD}} \mathrm{FN}$ (FN 30-8; M010), anti- ${ }^{-{ }^{2} l l a g e n}$ FN (FNC4-4; M114), anti- ${ }^{\text {Fibrin }}$ FN (FN 8-12; M001), anti- ${ }^{\text {Fibrin-Heparin }}$ FN (FN9-1; M009) and anti- ${ }^{\mathrm{Ct}} \mathrm{FN}$ (FN 1-1; M013) using five independent sandwich-type solid-phase enzyme-linked immunoassays (ELISA) according to a procedure described earlier [9]. The respective monoclonal antibody (diluted 10,000-times) 


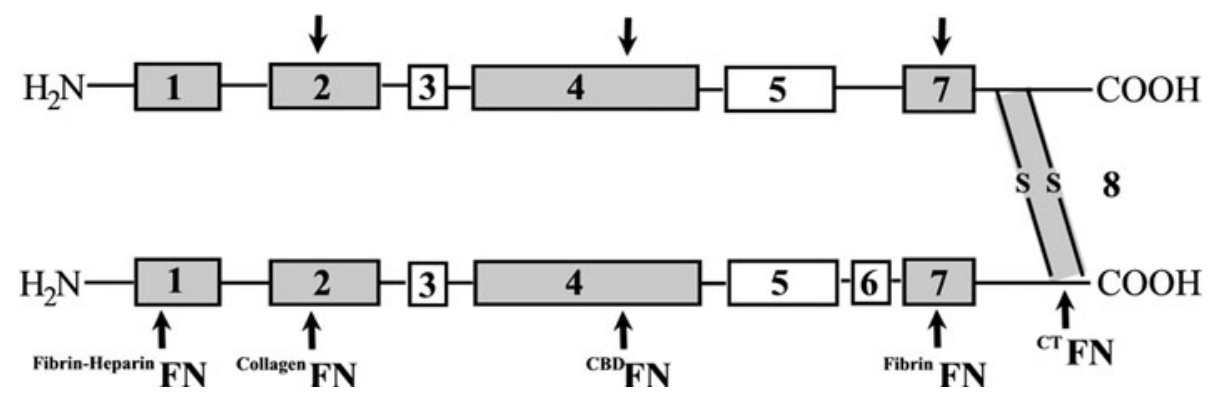

Fig. 1 The schematic illustration of the FN domain arrangement. The domains of FN: 1-fibrin-heparin-binding; 2-collagen-binding; 3-second heparin-binding; 4-cell-binding (CBD); 5-heparin-binding; 6-variable IIICS; 7-second fibrin-binding; 8-region containing

was used as coating agents in the wells of a microtiter plate (Nalge Nunc International, Naperville, USA) to bind FN from the sample in the next step. The amount of FN bound by the monoclonal antibody was quantified by rabbit polyclonal anti-FN antibodies (diluted 5,000-times) and subsequent reaction with the secondary antibodies, that is, peroxidase-conjugated goat anti-rabbit immunoglobulins (diluted 10,000-times). The amount of FN was assayed by a colorimetric reaction using o-phenylenediamine dihydrochloride $/ \mathrm{H}_{2} \mathrm{O}_{2}$ as the enzyme substrate and measured in Stat Fax 2100 Microplate Reader (Awareness Technology INC, USA) at $450 \mathrm{~nm}$ with $630 \mathrm{~nm}$ as a reference filter. All ELISA immunobinding and washing steps were carried out in TBS containing $0.1 \%$ Tween $20, \mathrm{pH}$ 7.3. A human plasma FN preparation (Sigma, St. Louis, MO, USA, from 10 to $50 \mathrm{ng} /$ well) was used as a standard. Results were given in $\mathrm{mg} / \mathrm{l}$.

Immunoblotting for FN molecular form determination

Plasma FN (300 ng), determined by ${ }^{\mathrm{CBD}}$ FN-ELISA as described previously, was subjected to SDS polyacrylamide gel electrophoresis (SDS-PAGE) in a 7.5\% gel under reducing conditions. After electrophoresis, the separated proteins were blotted onto nitrocellulose (Serva Electrophoesis GmbH, Heidelberg, Germany) as described earlier [9]. The blots were developed with mouse monoclonal antibody anti- ${ }^{\mathrm{CBD}}$ FN (FN 30-8, code M010, TaKaRa, Japan), diluted 1:10,000 in 5\% casein in TBS, and then with rabbit anti-mouse immunoglobulins conjugated to horseradish peroxidase (Sigma, 1:10,000 dilution in 5\% casein in TBS). The color reaction was developed with diaminobenzidine. Then, the blots were dried and analyzed. The molecular weights of the FN bands were determined using BioRad molecular-weight protein standards and intact human FN (MW 230 kDa; Sigma, St. Louis, MO, USA).

The relative amounts of the particular FN isoforms were expressed as the percentage of the total number of pixels in a lane. For this purpose, the blots were scanned disulfide bonds. The arrows indicate the FN domains recognized by monoclonal antibodies (TaKaRa, Shuzo Co., Shiga, Japan), which were used in presented work

and analyzed by densitometric GelScan v. 6.0 (Serva Electrophoresis).

\section{Statistics}

Data are presented as means \pm standard deviations (SD). The data were not normally distributed as calculated according to the Shapiro-Wilk $W$ test; therefore, the nonparametric Mann-Whitney $U$ test was used to determine differences between groups. The $P$ values lower than 0.05 were regarded as significant. Correlations between analyzed parameters and ESR as well as CRP were determined by the Spearman test. The diagnostic precision of the analyzed parameters was assessed using the receiver operating characteristic (ROC) curves. The area under the curve (AUC) quantified the diagnostic precision.

\section{Results}

FN domain concentration

The plasma FN domain concentrations showed no differences in relation to the patient's gender. Additionally, the FN domain concentrations showed no correlations with ESR and CRP levels (the range of $r$ coefficients, 0.01-0.2).

Table 2 gives the mean values of the FN domain concentration and the statistical differences between two groups, that is, between the SLE group in comparison with the normal group and RA group. The mean values of three analyzed parameters in SLE group $\left({ }^{\mathrm{CBD}} \mathrm{FN}: 190 \pm 58 \mathrm{mg} / \mathrm{l}\right.$, $P<0.000001 ;{ }^{C t} \mathrm{FN}: 285 \pm 72 \mathrm{mg} / \mathrm{l}, P<0.03$; and Fibrin${ }^{\text {Heparin }}{ }^{\mathrm{FN}}$ : $24 \pm 12 \mathrm{mg} / \mathrm{l}, P<0.000003$, respectively) and only Fibrin-Heparin FN $(36 \pm 22 \mathrm{mg} / \mathrm{l}, \quad P<0.00002)$ in RA group were significantly lower than those in normal group ( ${ }^{\mathrm{CBD}} \mathrm{FN}$ : $297 \pm 82 \mathrm{mg} / \mathrm{l} ; \quad{ }^{\mathrm{Ct}} \mathrm{FN}: \quad 363 \pm 141 \mathrm{mg} / \mathrm{l} ; \quad$ and Fib-Hep FN: $61 \pm 18 \mathrm{mg} / \mathrm{l}$, respectively). In contrast, the mean values of ${ }^{\text {Collagen }} \mathrm{FN}(307 \pm 155 \mathrm{mg} / \mathrm{l}, P<0.04),{ }^{\text {Fibrin }} \mathrm{FN}$ $(304 \pm 170 \mathrm{mg} / \mathrm{l}, \quad P<0.03)$ and ${ }^{\mathrm{Ct}} \mathrm{FN}(621 \pm 273 \mathrm{mg} / \mathrm{l}$, 
Fig. 2 Receiver operating characteristic (ROC) curves to determine cut off point values of concentrations of ${ }^{\mathrm{CBD}} \mathrm{FN}(\mathbf{a}, \mathbf{b})$, ${ }^{\mathrm{Ct}} \mathrm{FN}(\mathbf{c}, \mathbf{d})$ and ${ }^{\text {Fibrin-Heparin }} \mathrm{FN}$ $(\mathbf{e}, \mathbf{f})$. The area under curve (AUC) quantified precision in predicting RA compared with the normal group (a, $\mathbf{c}, \mathbf{e})$ and SLE compared with normal $(\mathbf{b}, \mathbf{d})$ and RA (f) groups
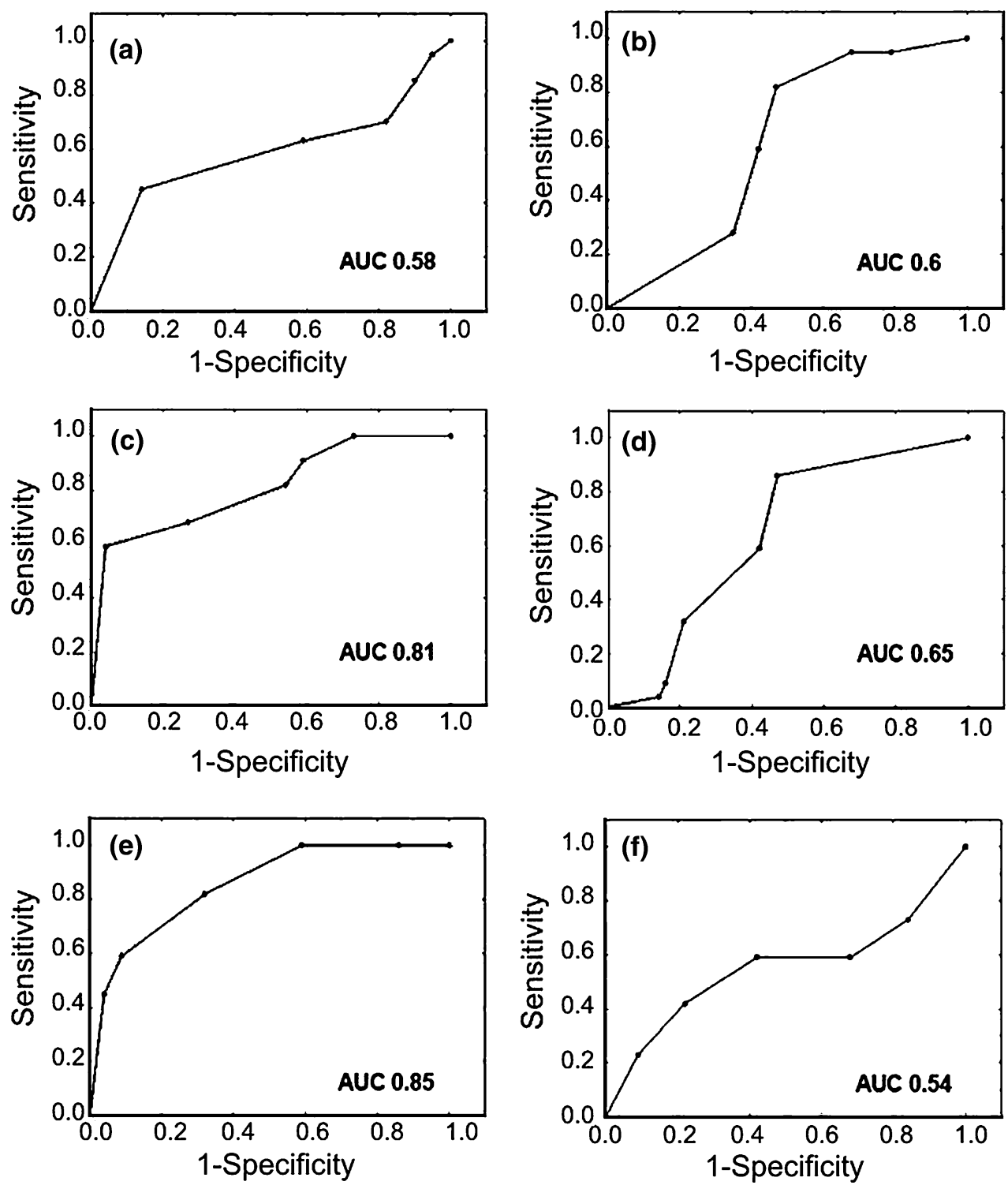

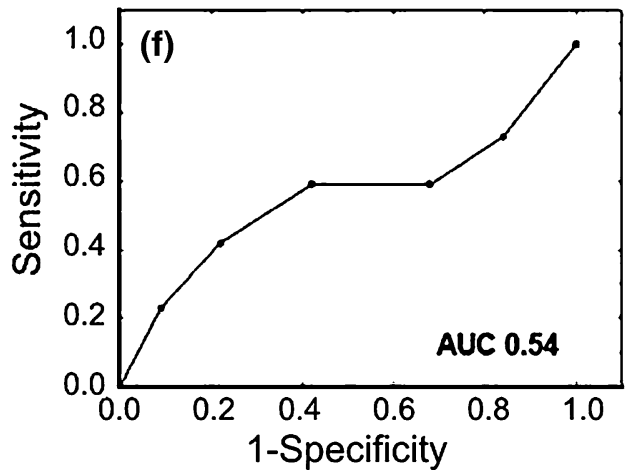

$P<0.001)$ were significantly higher in RA than those in normal group ( ${ }^{\text {Collagen }} \mathrm{FN}$ : $226 \pm 62 \mathrm{mg} / \mathrm{l}$; ${ }^{\text {Fibrin }} \mathrm{FN}$ : $206 \pm 80 \mathrm{mg} / \mathrm{l})$. In relation to RA group, all analyzed parameters in the SLE were significantly lower than those in RA group.

Using the ROC curves, the optimal cut off points of ${ }^{\mathrm{CBD}} \mathrm{FN}$ at $295 \mathrm{mg} / \mathrm{l}$ with $52 \%$ of sensitivity and $51 \%$ of specificity (AUC 0.58), ${ }^{\mathrm{Ct}} \mathrm{FN}$ at $460 \mathrm{mg} / \mathrm{l}$ with $70 \%$ of sensitivity and $73 \%$ of specificity (AUC 0.81 ) and Fibrin-Hepa${ }^{\text {rin }} \mathrm{FN}$ at $45 \mathrm{mg} / \mathrm{l}$ with $75 \%$ of sensitivity and specificity (AUC 0.85) were determined in predicting RA (Fig. 2a, c, e). On the other hand, the cut off points of ${ }^{\mathrm{CBD}} \mathrm{FN}$ at $200 \mathrm{mg} / \mathrm{l}$ with $58 \%$ of sensitivity and $56 \%$ of specificity (AUC 0.6), ${ }^{\mathrm{Ct}} \mathrm{FN}$ at $350 \mathrm{mg} / \mathrm{l}$ with $58 \%$ of sensitivity and $58 \%$ of specificity (AUC 0.65 ) and Fibrin-Heparin $\mathrm{FN}$ at $31 \mathrm{mg} / \mathrm{l}$ with $54 \%$ of sensitivity and $55 \%$ of specificity (AUC 0.54 ) were found in predicting SLE (Fig. 2b, d, f).
Plasma FN molecular forms

Representative immunoblot patterns of plasma $\mathrm{FN}$ are presented in the Fig. 3, and the mean values of the relative amounts of particular FN bands are given in Table 3. The immunoblotting with anti- ${ }^{\mathrm{CBD}} \mathrm{FN}$ monoclonal antibody revealed three types $(\mathrm{A}, \mathrm{B}, \mathrm{C})$ of $\mathrm{FN}$ immunopatterns. The FN immunopattern A (Fig. 3, lanes 1-2) consisting from 230 to $240 \mathrm{kDa} F N$ bands corresponding to not so well-separated native polypeptides was observed in $37 \%$ of SLE group (7/19 samples) and in $100 \%$ of samples of RA and normal groups.

The FN immunopattern $\mathrm{B}$ and $\mathrm{C}$ was found only in 21 and $42 \%$ of SLE samples (4/19 and 8/19 samples, respectively). The pattern B (Fig. 3, lanes 3-4) showed apart the presence of native $\mathrm{FN}$ bands (230 and $240 \mathrm{kDa}$ ), the high-molecular (260-310 kDa) as well as low-molecular 
Table 2 Plasma FN concentration in autoimmune rheumatic diseases

\begin{tabular}{|c|c|c|c|}
\hline \multirow{2}{*}{$\begin{array}{l}\text { FN domain } \\
\text { Groups }\end{array}$} & \multicolumn{3}{|c|}{ Plasma FN concentration (mg/l) } \\
\hline & $\begin{array}{l}\text { SLE } \\
n=19\end{array}$ & $\begin{array}{l}\text { RA } \\
n=22\end{array}$ & $\begin{array}{l}\text { Normal } \\
n=22\end{array}$ \\
\hline${ }^{\mathrm{CBD}} \mathrm{FN}$ & $\begin{array}{l}190 \pm 58 ; P<0.0003^{\mathrm{a}} \\
P<0.000001^{\mathrm{b}}\end{array}$ & $310 \pm 148$ & $297 \pm 82$ \\
\hline${ }^{{ }^{C o l l a g e n}} \mathrm{FN}$ & $214 \pm 42 ; P<0.004^{\mathrm{a}}$ & $\begin{array}{l}307 \pm 155 \\
P<0.04^{\mathrm{b}}\end{array}$ & $226 \pm 62$ \\
\hline${ }^{\text {Fibrin }} \mathrm{FN}$ & $170 \pm 28 ; P<0.0007^{\mathrm{a}}$ & $\begin{array}{l}304 \pm 170 \\
P<0.03^{\mathrm{b}}\end{array}$ & $206 \pm 80$ \\
\hline${ }^{\mathrm{Ct}} \mathrm{FN}$ & $\begin{array}{l}285 \pm 72 ; P<0.000001^{\mathrm{a}} \\
P<0.03^{\mathrm{b}}\end{array}$ & $\begin{array}{l}621 \pm 273 \\
P<0.001^{\mathrm{b}}\end{array}$ & $363 \pm 141$ \\
\hline Fibrin-Heparin FN & $\begin{array}{l}24 \pm 12 ; P<0.003^{\mathrm{a}} \\
P<0.000003^{\mathrm{b}}\end{array}$ & $\begin{array}{l}36 \pm 22 \\
P<0.00002^{\mathrm{b}}\end{array}$ & $61 \pm 18$ \\
\hline
\end{tabular}

The FN domain concentrations were determined by ELISA [9] using monoclonal antibodies specific to respective human cell- $\left({ }^{\mathrm{CBD}} \mathrm{FN}\right)$, collagen- ( $\left.{ }^{\text {Collagen }} \mathrm{FN}\right)$, fibrin- $\left({ }^{\mathrm{Fibrin}} \mathrm{FN}\right)$, carboxy-terminal $\left({ }^{\mathrm{Ct}} \mathrm{FN}\right)$ and fibrin-heparin ( ${ }^{\text {Fibrin-Heparin }} \mathrm{FN}$ ) binding domains of FN, respectively. The mean value \pm SD is given. For details, see "Materials and methods"

Significantly different from ${ }^{\mathrm{a}} \mathrm{RA}$ group and ${ }^{\mathrm{b}}$ normal group as calculated by Mann-Whitney $U$ test

(158-209 kDa) FN bands. The immunopattern C (Fig. 3, lanes 5-6) was characterized by the presence of native FN (bands of $\mathrm{M}_{\mathrm{w}} 230$ and $240 \mathrm{kDa}$ ) as well as high-molecular FN bands $\left(\mathrm{M}_{\mathrm{w}}\right.$ from 260 up to $\left.310 \mathrm{kDa}\right)$. The percentage (from 0.7 to $14.5 \%$ ) of their appearance is shown in Table 3.

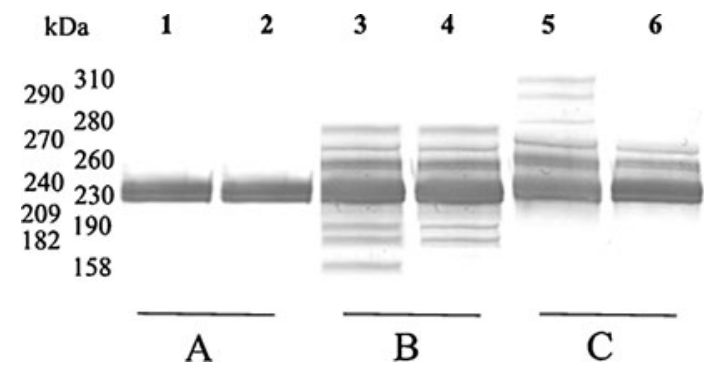

Fig. 3 Representative immunoblot patterns of plasma FN. SDSPAGE in $7.5 \%$ gel was done under reducing conditions. The immunoblots were developed with monoclonal antibody anti- ${ }^{\mathrm{CBD}} \mathrm{FN}$. $A, B$ and $C$ pattern types (quantitatively characterized in Table 3) represent immunoblotting of plasma samples: 1 -normal, 2-RA, 3-6-SLE

\section{Discussion}

Our findings indicate that plasma FN concentration was significantly lower in SLE than in RA patients and normal individuals (Table 2). Moreover, the low value of FN concentration was more frequently associated with the unusual FN immunoblotting patterns characterized by the presence of FN fragments and/or the high-molecular weight band series which appeared in immunoblotting of the most SLE, but in none of the RA and normal plasmas (Table 3, Fig. 3).

However, previous reports indicated elevated plasma FN level in SLE patients is [13] significantly higher in patients

Table 3 Quantitative analysis of plasma FN molecular forms in SLE and RA patient groups

\begin{tabular}{|c|c|c|c|c|}
\hline \multirow[t]{5}{*}{ No } & \multirow{2}{*}{$\begin{array}{l}\mathrm{M}_{\mathrm{w}} \text { of } \mathrm{FN} \text { bands }(\mathrm{kDa}) \\
\text { In groups }\end{array}$} & \multicolumn{3}{|c|}{ Relative amounts (\%) of plasma FN bands showing A-C types of patterns } \\
\hline & & A & B & $\mathrm{C}$ \\
\hline & Normal & $100 \%$ & $0 \%$ & $0 \%$ \\
\hline & RA & $100 \%$ & $0 \%$ & $0 \%$ \\
\hline & SLE & $37 \%$ & $21 \%$ & $42 \%$ \\
\hline 1 & $310 \pm 3$ & & & $1.6 \pm 1.1$ \\
\hline 2 & $291 \pm 2$ & & & $0.7 \pm 0.5$ \\
\hline 3 & $279 \pm 2$ & & $2.6 \pm 1.1$ & $1.9 \pm 1.3$ \\
\hline 4 & $270 \pm 4$ & & $7.7 \pm 6.9$ & $4.3 \pm 3.5$ \\
\hline 5 & $260 \pm 3$ & & $14.5 \pm 9.9$ & $13.1 \pm 9.7$ \\
\hline 6 & $240 \pm 1$ & $63 \pm 7.6$ & $41.4 \pm 7.7$ & $52.5 \pm 11.1$ \\
\hline 7 & $230 \pm 1$ & $37 \pm 7.6$ & $31.4 \pm 9$ & $32.6 \pm 6.4$ \\
\hline 8 & $209 \pm 5$ & & $7.5 \pm 5.4$ & \\
\hline 9 & $190 \pm 3$ & & $3.5 \pm 1.9$ & \\
\hline 10 & $182 \pm 4$ & & $4.1 \pm 1.5$ & \\
\hline 11 & $158 \pm 6$ & & $1.4 \pm 0.1$ & \\
\hline
\end{tabular}

FN immunoblotting (Fig. 3) of SLE, RA and normal plasmas which revealed A, B and C pattern types was scanned and analyzed by densitometry Gel Scan 6.0 1D Analysis Software (Serva Electrophoresis). Relative amounts of particular FN bands were expressed in the percentage of the total number of pixels in a lane 
with active SLE than with nonactive disease [14]. It should be underlined that our results of FN determination by the set of domain-specific monoclonal antibodies do not correspond to total FN level measured by polyclonal antibodies used in previous studies. It may be because the FN domain epitopes can be masked by interfering with antibodies, other molecules, the FN ligands, such as respective cellular integrins, collagen and its fragments, fibrin or glucosaminoglycans [15]. Additionally, the degradation of FN molecule by endogenous metalloproteinases, active during inflammatory diseases, can lead to damage of domain epitopes and/ or to exposition of cryptic functional sites. Moreover, a conformational alteration in one domain could have an effect on conformation and stabilization of the nearest neighbor sites [16].

Among analyzed FN domains, the most helpful seems to be the determination of Fibrin-Heparin $\mathrm{FN},{ }^{\mathrm{CBD}} \mathrm{FN}$ and ${ }^{\mathrm{Ct}} \mathrm{FN}$ levels. The low expression of ${ }^{\text {Fibrin-Heparin }}$ FN (Table 2) was found to be a common characteristic parameter for SLE and RA. Moreover, the low ${ }^{\mathrm{CBD}} \mathrm{FN}$ and ${ }^{\mathrm{Ct}} \mathrm{FN}$ can help to differentiate SLE with RA. However, we rather recommend the ${ }^{\mathrm{Ct}} \mathrm{FN}$ determination. Using it seems to be more universal than ${ }^{\mathrm{CBD}} \mathrm{FN}$ determination, because on the one hand, the low ${ }^{\mathrm{Ct}} \mathrm{FN}$ expressions can help to differentiate SLE from RA and normal samples, and on the other hand, the high level RA from the normal individuals. According to the ROC analysis, the ${ }^{\mathrm{Ct}} \mathrm{FN}$ concentration lower than $350 \mathrm{mg} / \mathrm{l}$ in SLE and higher than $460 \mathrm{mg} / \mathrm{l}$ in RA can predict the diseases with quite good sensitivity (58 and $70 \%$, respectively) as well as specificity (58 and $73 \%$, respectively). As the previous report indicates, the low ${ }^{\mathrm{Ct}} \mathrm{FN}$ concentration and the concomitant presence of FN fragments have been observed by us in synovial fluid of RA patients [9]. The FN fragments were also reported in the plasma of patients with active SLE [17]. Here, we have also shown that about $60 \%$ of analyzed SLE samples showed besides the 230 and 240$\mathrm{kDa} F N$ bands corresponding to native $\mathrm{FN}$, the presence of normally absent four FN fragments (having molecular weight from 158 to $209 \mathrm{kDa}$ ) and three to five high-molecular weight FN forms (from 260 to $310 \mathrm{kDa}$ ). They formed, respectively, about 16 and $24 \%$ of all FN forms reactive with anti-FN monoclonal antibody (immunopatterns B and C in Fig. 3 and Table 3). In contrast, in RA, the plasma FN was untouched (Fig. 3-lane 2), and its significantly higher level resulted probably from the increased total FN production by hepatic cells in a response to systemic inflammation. It could not be excluded that the plasma FN molecules in autoimmune patients can represent apart the FN derived from hepatic cells, the significant part of the FN of nonhepatic origins, that is, epithelial and/or endothelial cell productions. They could be synthesized by highly active immunological cells and/or epithelial and/or endothelial cells as native, intact molecules, and/or additionally they can appear as fragments derived from degraded extracellular matrix of blood vessel cells in SLE. The tissue erosive process happens exclusively in joints and around the joints of RA patients, where many extracellular components, among them synovial, but not plasma FN, undergo degradation $[18,19]$. The findings are important because SLE and RA differentiation may be sometimes difficult, particularly at the beginning of SLE when patients have joint pain without any systemic indicators [20].

The FN fragments are thought to have many diverse activities [21-23] and among them an ability to form crosslinking complexes with $\mathrm{FN}$, various extracellular matrix components and some blood plasma components such as fibrin and fibrinogen [24, 25]. A formation of multimeric cross-linking polymers lies on the base of repair processes at which FN takes a main role [26]. In 60\% SLE patient plasma samples, we observed the presence of $\mathrm{FN}$ forms having molecular weight from 260 to $310 \mathrm{kDa}$ (Fig. 3, Table 3). The high-molecular FN forms may partly result from the expression of alternatively spliced (ED-A, ED-B and IIICS) segments, either are highly glycosylated glycoforms, or may be formed by an FN linkage with some blood plasma, extracellular matrix components, or their fragments $[27,28]$, or even smaller molecules such as homocysteine [29].

In conclusion, the data presented here pointed out that the analysis of FN level based on its domain epitope expression and of FN molecular status revealed by immunoblotting can be helpful to differentiate SLE in respect to RA and healthy individuals. The observed FN molecular pattern can be related to the general molecular processes by which the plasma FN is used for tissue needs.

Open Access This article is distributed under the terms of the Creative Commons Attribution Noncommercial License which permits any noncommercial use, distribution, and reproduction in any medium, provided the original author(s) and source are credited.

\section{References}

1. Walsch NC, Crotti TN, Goldring SR, Gravallese EM (2005) Rheumatic diseases: the effects of inflammation on bone. Immunol Rev 208:228-251

2. Liu Ch-Ch, Ahearn JM (2009) The search for lupus biomarkers. Best Pract Res Clin Rheumatol 23:507-523

3. Markatseli TE, Papagoras C, Drosos AA (2010) Prognostic factors for erosive rheumatoid arthritis. Clin Exp Rheumatol 28:114-123

4. Lindstrom TM, Robinson WH (2010) Biomarkers for rheumatoid arthritis: making it personal. Scand J Clin Lab Invest 70:79-84

5. Yamada K (2000) Fibronectin peptides in cell migration and wound repair. J Clin Invest 105:1507-1509

6. Wierzbicka-Patynowski I, Schwarzbauer JE (2003) The ins and outs of fibronectin matrix assembly. J Cell Sci 116:3269-3276

7. Moretti FA, Chauhan AK, Iaconcig A, Porro F, Baralle FE, Muro AF (2007) A major fraction of fibronectin present in the extracellular matrix of tissues is plasma-derived. J Biol Chem 282:2805728062 
8. Pankov R, Yamada KM (2002) Fibronectin at a glance. J Cell Sci 115:3861-3863

9. Przybysz M, Borysewicz K, Szechiński J, Kątnik-Prastowska I (2007) Synovial fibronectin fragmentation and domain expressions in relation to rheumatoid arthritis progression. Rheumatology 46:1071-1076

10. Arnett FC, Edworthy SM, Bloch DA, Shane Mc, Fries JF, Cooper NS, Healey LA, Kaplan SR, Liang MH, Luthra HS et al (1988) The American Rheumatism Association 1987 revised criteria for the classification of rheumatoid arthritis. Arthritis Rheum 31:315324

11. Renton P (1998) Imaging in rheumatoid arthritis. In: Maddison PJ, Isenberg DA, Woo P, Glass DN (eds) Oxford textbook of rheumatology. Oxford University Press, Oxford, pp 24-51

12. Tan EM, Cohen AS, Fries JF, Masi AT, McShane DJ, Rothfield NF et al (1982) The 1982 revised criteria for the classification of systemic lupus erythematosus. Arthritis Rheum 25:1271-1277

13. Nishinarita S, Yamamoto M, Takizawa T, Hayakawa J, Karasaki M, Sawada S (1990) Increased plasma fibronectin in patients with systemic lupus erythematosus. Clin Rheumatol 9:214-219

14. Carsons S, Parenti D, Lavietes BB, Diamond HS, Singer A, Boxer M (1985) Plasma fibronectin in systemic lupus erythematosus: relationship to clinical activity, DNA binding and acute phase proteins. J Rheumatol 12:1088-1092

15. Vakonakis I, Staunton D, Ellis IR et al (2009) Motogenic sites in human fibronectin are masked by long range interactions. J Biol Chem 284:15668-15675

16. Jankovi'c MM, Kosanovi'c MM (2008) Fibronectin pattern in benign hyperplasia and cancer of the prostate. Dis Markers 25:49-58

17. Carsons S (1987) High level of fibronectin fragments in the plasma of a patient with active systemic lupus erythematosus. J Rheumatol 14:1052-1054

18. Dang Y, Cole AA, Homandberg GA (2003) Comparison of the catabolic effects of fibronectin fragments in human knee and ankle cartilages. Osteoarthr Cartil 11:538-547

19. Yasuda $T$ (2006) Cartilage destruction by matrix degradation products. Mod Rheumatol 16:197-205
20. Yi M, Ruoslahti EA (2001) Fibronectin fragment inhibits tumor growth angiogenesis, and metastasis. Proc Natl Acad Sci USA 98:620-624

21. Rojas-Villarraga A, Toro C-E, Espinosa G et al (2010) Factors influencing polyautoimmunity in systemic lupus erythematosus. Autoimmun Rev 9:229-232

22. Steffensen B, Xu X, Martin PA, Zardeneta G (2002) Human fibronectin and MMP-2 collagen binding domains compete for collagen binding sites and modify cellular activation of MMP-2. Matrix Biol 21:399-414

23. Johnson A, Smith R, Saxne T, Hickery M, Heinegård D (2004) Fibronectin fragments cause release and degradation of collagenbinding molecules from equine explant cultures. Osteoarthr Cartil 12:149-159

24. Toyoshima K, Kimura S, Cheng J, Oda Y, Mori KJ, Saku T (1999) High molecular-weight fibronectin synthesized by adenoid cystic carcinoma cells of salivary gland origin. Jpn J Cancer Res 90:308319

25. Mao Y, Schwarzbauer JE (2005) Fibronectin fibrillogenesis, a cell-mediated matrix assembly process. Matrix Biol 24:389-399

26. Schaal-Jensen R, Kiehr B, Boesen HT et al (2007) Characterization of high molecular weight plasma protein complexes induced by clotting factor rFXIII-treatment in the Cynomolgus monkey. J Thromb Haemost 5:2070-2078

27. Ito H, Rucker E, Steplewski A et al (2005) Guilty by association: some collagen II mutants alter the formation of ECM as a result of atypical interaction with fibronectin. J Mol Biol 352:382-395

28. Makogonenko E, Ingham KC, Medved L (2007) Interaction of the fibronectin $\mathrm{COOH}$-terminal fib-2 regions with fibrin: further characterization and localization of the fib- 2 binding sites. Biochemistry 8:5418-5426

29. Majors AK, Sengupta S, Willard B, Kinter MT, Pyeritz RE, Jacobsen DW (2002) Homocysteine binds to human plasma fibronectin and inhibits its interaction with fibrin. Arterioscler Thromb Vasc Biol 22:1354-1359 